\title{
PROGRAM, BE PROGRAMMED OR FADE AWAY: COMPUTERS AND THE DEATH OF CONSTRUCTIVIST ART
}

\author{
Richard Wright \\ 6 Medina Court, Seven Sisters Road, \\ London N7 7PU \\ U.K. \\ richard@futurenatural.net \\ www.futurenatural.net
}

Why did Constructivist artists of the 60s and 70s find it so hard to switch from calculators and graph paper to BASIC and PCs? Was there something in their pre-computer 'programmatic' ways of working that did not readily transfer to computer programming - something that could now be recovered and used to refresh current software based art practices that constantly struggle with the limitations of proprietary operating systems, desktop interfaces and network protocols?

\section{INTRODUCTION}

"Today we stand between a society that does not need us and one that does not yet exist."

El Lissitzky, Theo Van Doesburg and Hans Richter, "Statement by the International Faction of Constructivists", 1922 [1].

History has not been kind to the Constructivists. Unlike the other big hitters of the Modern art movement, they have almost become figures of fun in art history - the first artist geeks with their rulers and protractors, polishing their little Perspex maquettes and planning their rectangular utopias. It seems as though Constructivism has been unable to maintain its relevance, its enthusiasm for science and engineering superseded up by the rise of mass digital computing and telecommunications. Paradoxically it feels as though Constructivism has become the victim of a kind of success story. Many of Constructivism's core values of interdisciplinary working and research, of objective process as opposed to subjective meaning and deference to the machine as a source of artistic inspiration have now been absorbed into the assumptions of current new media art practices and funding strategies in the UK.

The Constructivist approach is an aesthetic and a technique that values openness, clarity and the structuring process in opposition to predetermined content, completeness and individual subjectivity. If we accept that this idea of the 'programmatic' - the recasting of artistic working into an objective, reproducible discipline - was a central tenet in Constructivism then it is a little hard to see why the movement should have declined precisely at the point at which the 'programmatic' seemed to reach its fullest potential the programming of the digital computer. 


\section{THE FIRST RISE AND FALL OF CONSTRUCTIVISM}

It was at "The Congress of International Progressive Artists" in Dusseldorf in 1922, that El Lissitsky, Theo Van Doesburg and Hans Richter issued a joint statement entitled "Statement by the International Faction of Constructivists". One passage in the statement sums up the basis of their shared interests succinctly - their opposition to the "tyranny of the subjective" and their belief in the "systematisation of the means of expression to produce results that are universally comprehensible" [2]. Its artistic inspiration could be traced back to Vladimir Tatlin's sculpture known as the "Corner Counter Relief" of 1915. Tatlin's sculpture was both a development of Picaso's Cubist aesthetic and also an 'opening up' of the previously unified technique of art making into a series of manufacturing operations. Not only did he 'return to reality' by including real industrial materials like synthetic Cubism had but also 'returned' art to everyday activity by making it possible for the audience to discern how one might go about making ones own DIY relief sculpture from bits of tin sheeting, wooden laminates, rods and bolts. This explains an important sense in which a "systematic means of expression" could lead to those "universally comprehensible" results - as though it were an IKEA flat pack wardrobe complete with multi-lingual instruction book and a set of Allen keys.

Of equal significance for us in this early period is Gabo's "Kinetic Sculpture" of 1920. Through its rapid oscillations, a vertical wire generates the image of a 'standing wave', a perceived physical space yet one without physical mass or solid boundary. At once this work was able to demonstrate not only the dependence of physical form on structure, time and motion, but also its construction as an intangible image in the mind of the observer. Yet Gabo pulled back from the further deployment of electronics, giving his reasons in terms of his fear of "killing through mechanical parts the pure sculptural content" [3]. Unlike the open construction of Tatlin's reliefs, Gabo could not see how you could open up the construction of things like electric motors, coils and capacitors and still meet the aims of an art based on the visual knowledge of physical forces. A bunch of electrical parts soldered together just did not express anything. It was the first recorded instance of what would later become known as the Black Box Syndrome.

\section{PROGRAMMING BEFORE COMPUTERS}

After the Second World War, Constructivist refugees such as Gabo who had fled to England began to exert an influence. It began in 1948 when Victor Pasmore, a successful figurative painter, shocked his patrons by announcing his complete conversion to abstraction. Later in 1967 he wrote of this need to search for a new artistic premise "...concentrating on the nature of objects and processes as 'things in themselves' whether they be a sheet of paper, a blot of colour, the mark of a tool, the movement of the hand or the motion of a machine" [4]. By 1951 Pasmore had been joined by artists such as Kenneth and Mary Martin, Adrian Heath and a young exstudent of his called Anthony Hill. It was during this search for a new direction and identity that the young Hill emerged as the chief theorist of the group and started 
corresponding with three very different influences - the Swiss Concrete artist Max Bill, the American Structuralist Charles Biederman and the spiritual father of conceptualism Marcel Duchamp.

Anthony Hill became drawn to the mathematical work of the Swiss Concrete artists Max Bill and Richard Lohse. Their use of mathematics had moved away from the metrical relationships and geometrical proportions of the pre-war period to a level that was no longer tied to the visual world, "The mathematical approach in contemporary art is not mathematics in itself... It is primarily a use of processes of logical thought towards the plastic of rhythms and relationships" [5]. By taking a definition of mathematics as the "theoretical phenomenology of structure", Hill sought to find a new place for an abstract formal language in art by fusing it into the structural process of creative thought itself.

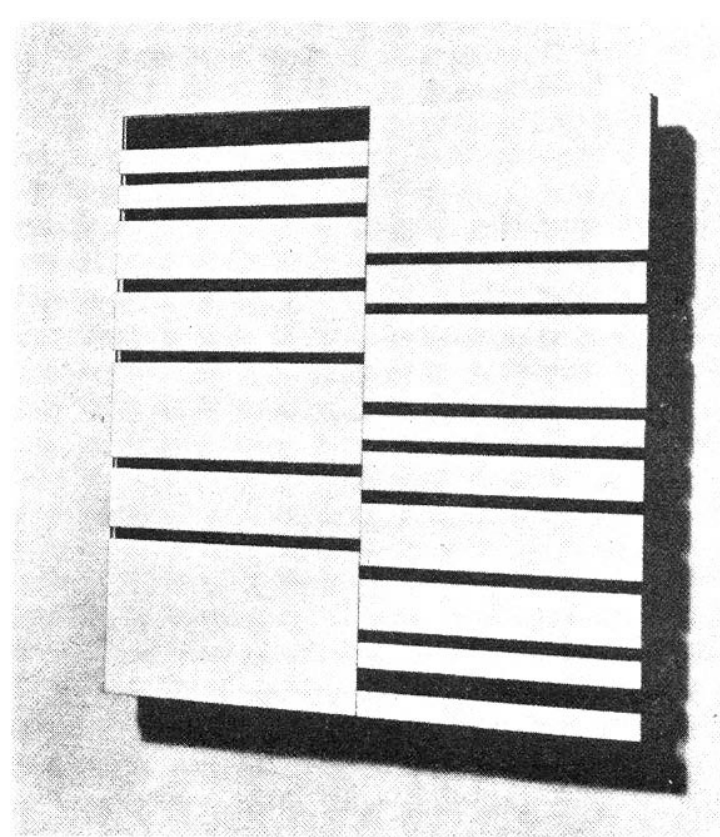

Fig. 1. Anthony Hill, Prime Rhythms (Constructional Relief). Perspex and vinyl sheet, 1958-60. (Coll. Adrian Heath, Clio Heath)

In "Prime Rhythms", a low monochrome relief constructed in 1958, Hill had moved towards mathematical 'themes' [Fig 1]. By 'theme', Hill was referring not to the subject of the work but to its starting point at the level of formative structural processes. In this particular work, Hill took all the prime numbers less than one hundred as his "thematic idea" and used them in a succession of what he termed "structural modifications" [6]. This consisted of operations such as throwing out all the even numbers, selecting only consecutive primes and then a whole myriad of systematic procedures based on "distribution, deviation and density ratios, equalities and inequalities". These were always derived with reference to the visual properties of the relief such as the use of planar intervals to embed the sequence in the form of two sets of horizontal bands. Hill was at pains to point out that the work was not about the prime numbers as such. It was simply about what you saw when you looked at the relief, a particular visual rhythm, prime numbers forming the "idea in the work as opposed to the idea of the work". As to 
the significance of the procedures that he applied to this idea, "Certainly other procedures could have been found to achieve the same sort of end, but the satisfaction of the one chosen lies for me in the fact that it had to be worked on and did not involve chance or 'aesthetic trial and error' at every level, nor did it carry with it some notion of finite ideal order".

At each stage in the development of his relief sculptures, aesthetic judgements were allowed to favour the direction taken. It was not simply that Hill chose the most attractive option resulting from a set of mathematical permutations, but that he adjusted the perceptual properties of the work with reference to mathematical ideas in order to achieve a bodily perception of their spatial structure. His works were not like the result of running a program - not even an interactive program that relies on being steered. Nor were they like the visualisation of a program through its decomposition into a series of discrete graphic elements like an elaborate flow chart. They were more the result of a mathematical logic or 'thematic structure' being articulated or 'worked on' by applying the varied refractions of different visual or sensory logics.

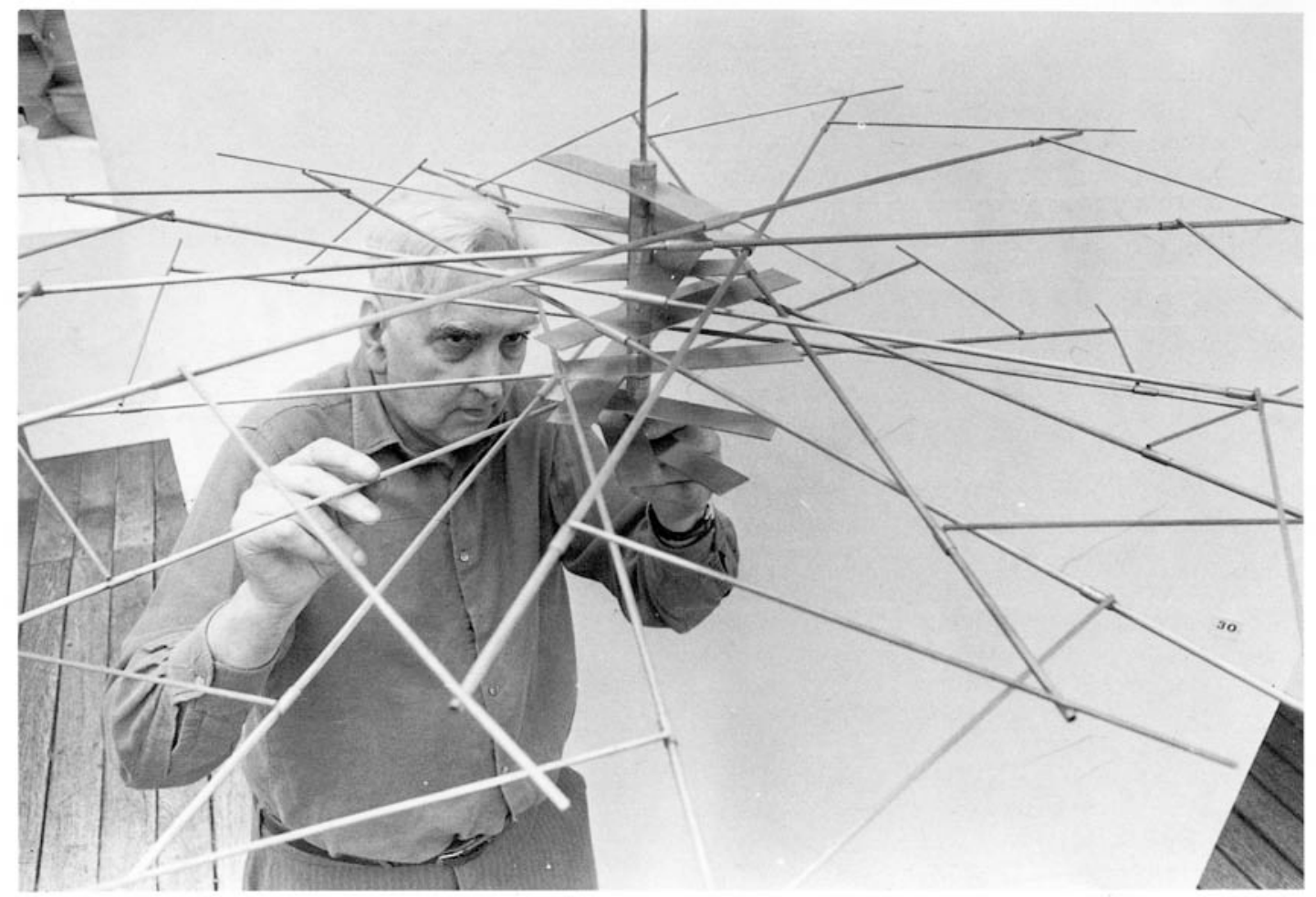

Fig. 2. Kenneth Martin with Screw Mobile, 1967. Courtesy Annely Juda Fine Art, London. Copyright the Estate of Kenneth Martin.

It is worth comparing Hill with the practices of his contemporary Kenneth Martin. Whereas Hill started with the theoretical structures of maths, Martin started with movement. During the fifties Martin started to produce a series of "Screw Mobiles" and "Transformables" which were made by applying sequences of transformations to simple metal objects - typically bars, rings and rods [Fig 2]. The resulting sculptures exhibited the spatial displacements he applied by shifting and rotating them, twisting, expanding and contracting them in the form of a progressive series. Rings and bars might first be 
positioned in such a way that their relationship defined a set of possible actions or measured intervals. Sometimes the movements they defined could be described and replaced by the shape of a parabolic band or a cylindrical extrusion. The effect of forces like gravity to roll or oscillate objects when suspended was noted. These domains of movement were repeatedly exercised, transcribed, ordered by number sequences, transformed into shapes and then re-examined for the next stage of development.

Martin tried to structure the creative process itself by recasting each stage as one of a series of rhythmic changes. In this sense his approach was more general than that of Hill's - "To be interested in the kinetic is to be consciously interested in sensation as such, for not only is form-making a corollary of movement, but so are sensation and feeling" [7]. It was as though he was trying to choreograph, as they happened, all the shifts and unfoldings that his mind, body and senses went through over the course of a creative enterprise. For Martin the kinetic experience was in the practice itself and he was therefore able to express movement without having to engineer actual movement, thus removing the necessity for any of Gabo's hated 'mechanical parts'. Although he described his analogue methods as 'programmed' transformations, this form of programming would be as difficult for us to appreciate today as if you had to create a computer program not by writing a highly restricted text but through all the actions of mixing, kneading and rolling the dough for a perfect pastry crust. They were programmed in the sense that "...a logic and a counter-logic are set in operation and the results are accepted" as his wife Mary Martin stated [8] [Fig. 3].

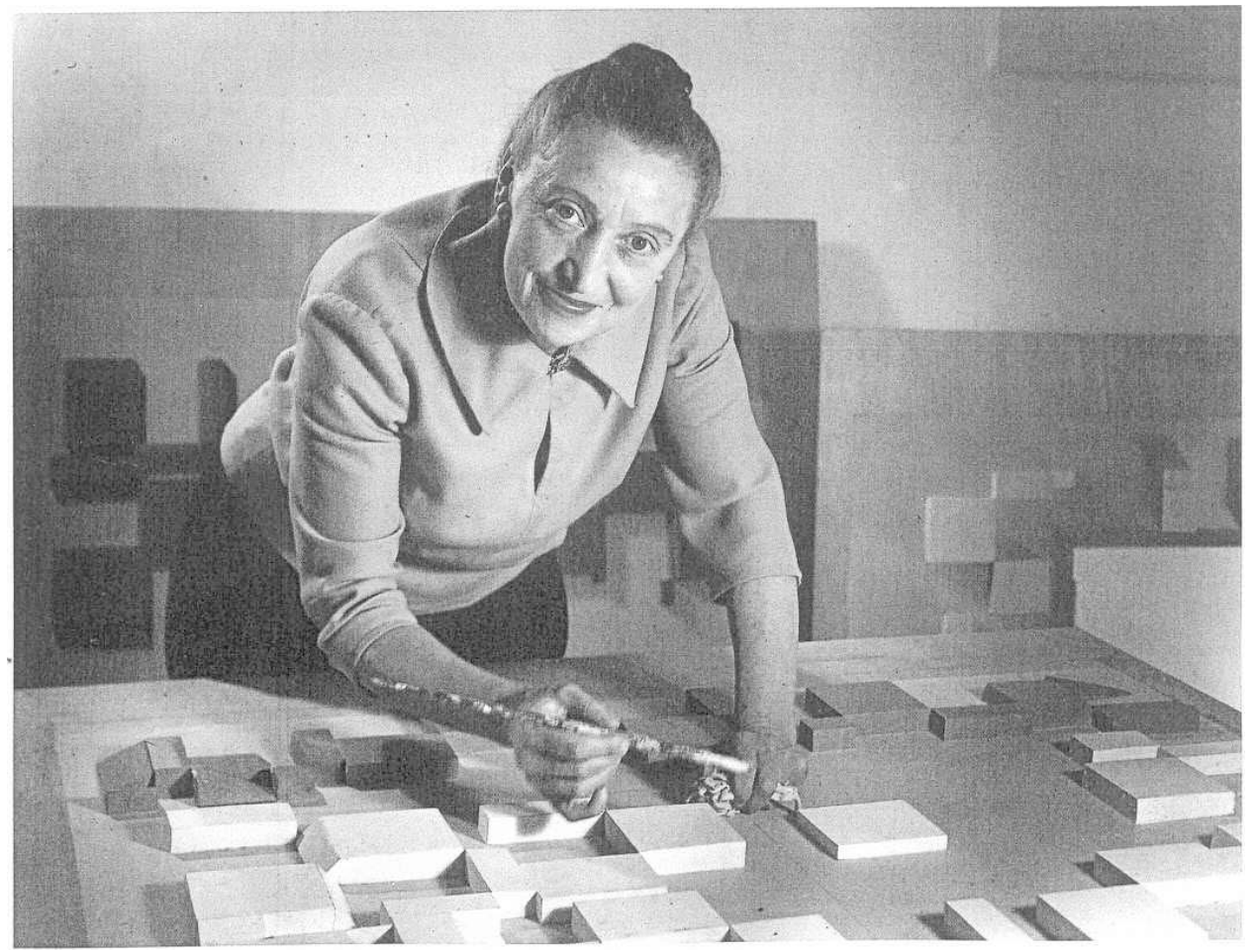

Fig. 3. Mary Martin working on maquettes for Tidal Movements, 1960

Courtesy Annely Juda Fine Art, London. Copyright the Estate of Mary Martin. 


\section{SYSTEMS FROM ANOTHER PLANET}

In 1969 Jeffrey Steele founded the Systems group, including John Ernest, Gillian Wise, Malcolm Hughes, Jean Spencer, Michael Kidner and several others. As they took advantage of the techniques provided by post war mathematics and cybernetics, the intimate connection between their generative systems and the works they produced started to become strained. The different levels of materiality that could exist as a single 'system' began to multiply - knowledge, documentation, feeling, perception - it began to tax the Systems artists as to how they could tie together all these different bodies. The question of whether it was important that the 'underlying system' should be apparent in the final work, and in what sense the 'system' could realistically be called the content of the work began to be asked more and more. One way to prevent the work splitting between a conceptual procedure and a perceptual result was to follow what Kenneth Martin had advised in 1964 that "...construction must start with the simplest and most practical means and to avoid confusion aim at the simplest results" [9]. But as the resources of formal logic became more and more sophisticated and prolific there was mounting pressure to move beyond the processing abilities that the human mind could keep up with.

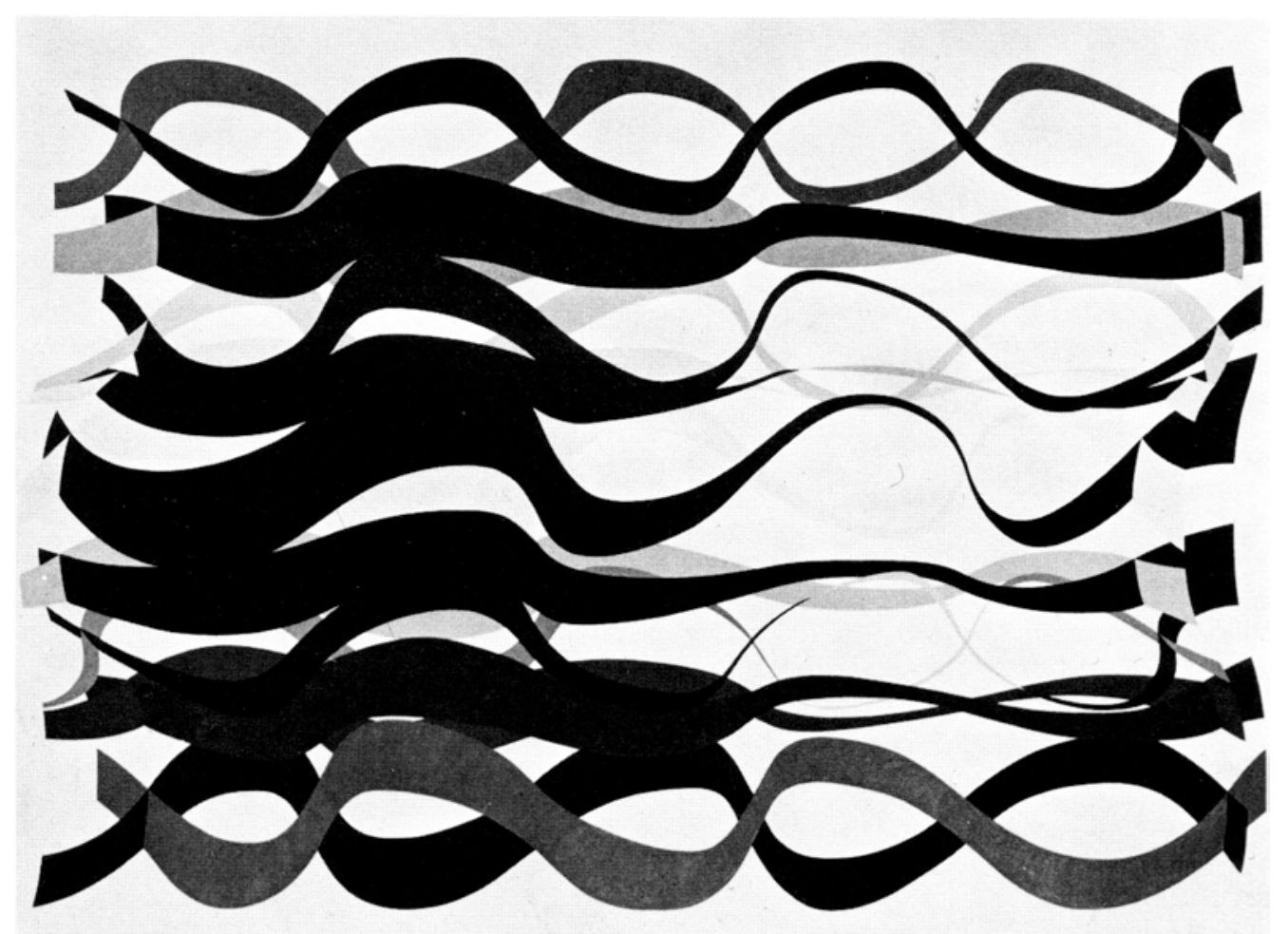

Fig. 4. Jeffrey Steele, Medusa. Oil on canvas, 914 x 1219 mm, 1969. Courtesy the artist.

Some artists like Steele now pushed ahead in the direction of what we would now recognise as a fully materialist 'generative' art practice, including a renewed acceptance of the irrational [Fig. 4]. "To grasp the full extent and power of systems entails giving as much attention to chance, deranged, anarchic systems as to those with a more manifest regard for law and order" [10]. By examining the kinds of information that these systems could generate they might find a way to test or 'validate' them, not for 
their truth value or meaning but for their productive capacities, as engines of chaotically fertile invention. Systems could now be freed to move beyond human categories of order and disorder. To try to constrain them to the production of comfortable human meaning would be as pointless as “...trying to communicate by signals with an intelligence on another planet with whom we have no common experience and therefore nothing to communicate about" [11].

There arose a danger that the system would disconnect from the artist altogether, becoming a completely autonomous machine. An overview of the situation was provided by Kenneth Martin in 1968 when he divided systematic work into three types [12]. Firstly there was the completely predefined system which once set in motion could generate work independently of any further artistic input. Secondly there was a system that may be initially predefined but constantly altered through feedback, bringing into contact with other systems, etc - the 'program' is thereby written in conjunction with the work itself. Finally there is the system which builds up from a primary act without any previous planning, like a self propelled aggregation of logical steps - the writing of the program is indistinguishable from the practice itself. For Martin, the more the system is predetermined like the first example, the more problematic things become, not just because of the marginalisation of the artist but because of the systems distance from the specificity of any given situation - "...it is difficult to predetermine a system for forms whose properties one is in the way of discovering". It is more a question of how one can be expected to work with a form of logic without the direct motivation and stimulus of the object of that logic - such as its material consequences or its physical or historical situation. One is inventing a process, not just a program. It is this awareness of trying to retain a purchase on formal systems as the computer made them more and more autonomous that would become an increasingly pressing concern.

\section{PROGRAM, BE PROGRAMMED OR FADE AWAY}

Despite the mounting complexity of their 'programs' and the opportunities for practical implementation afforded by computer programming, there are several reasons why the reticence of Systems artists to engage with computing might have made sense. To begin with, formal programming languages made it difficult to mix together very different kinds of logic. Everything had to be reduced and encoded into the same terms. Constructivists were by this time used to switching freely between different number systems, geometries, topologies and the plastic possibilities of the picture plane. To have to find a way to translate an act as fundamental as a shift in ones cognitive mode into Cartesian coordinates and conditional statements sounded pedestrian.

The Constructivists were used to identifying their systems with the concrete actions, matter and sensations that had inspired them. Artist Jean Spencer had stated that "...a system cannot be taken out of the context it originated in" [13]. The making of a constructed relief was derived from structuring processes like moulding, resistance, mass, occlusion and the acting of rational operations upon them. The inclusion of physical and analogue systems gave them a richer perspective than one restricted to formal logic. When objects are defined inside the computer one must approach their potentialities from some point of interest in order to avoid becoming lost in them, as 
Kenneth Martin had hinted. If one was modelling the properties of metal rods and rings in a computer simulation one could model any properties one liked but a decision must be made. And once that decision is made then the rods and rings themselves tend to be lost as sources of unknown procedural insight. What then, the Constructivists might have asked, can take their place?

Some artists did try to use techniques such as interactive sculpture to make computer programming part of a wider system of human behaviour and cognition with some success such as Edward Ihnatowicz's famous "Senster" sculpture of 1970. But the more complicated these constructions became with all their logical, electronic and mechanical components, the more they began to suffer from Gabo's 'Black Box' problem of sculptural awkwardness and procedural inscrutability. These sculptures did not communicate an underlying coded 'theme' and did not offer the audience a completely 'open' construction, instead moving towards explicating themselves as effects.

It should have been possible to put software into the mix of a wider practice of systematic art. Yet computer software is a jealous mistress. From the beginning of the eighties, the development of interactive applications software replaced all manual operations with the menu lists, parameters sliders and icons of the modern windowing environment [14]. By the middle of the eighties computer based art would largely be produced on desktop boxes and consumed through desktop boxes. For artists who avoided pre-packaged applications and took on the challenge of computer programming itself, the increasing dominance of structured programming styles threatened to narrow their practice due to the kind of expertise required - having to relate to each proprietary component of a system through its technical specification rather than its technical potential. The Systems artists couldn't use the intimate physical and perceptual qualities they were used to as a basis for their investigations in programming languages and this lack of bearings threatened to turn the unfettered formal power of computer logic into a blizzard of arbitrarily designed information ordered only by contingent commercial agendas. Under these conditions it was hard for many artists to find much enthusiasm for a visual space that was increasingly colonised by unsympathetic interests. 


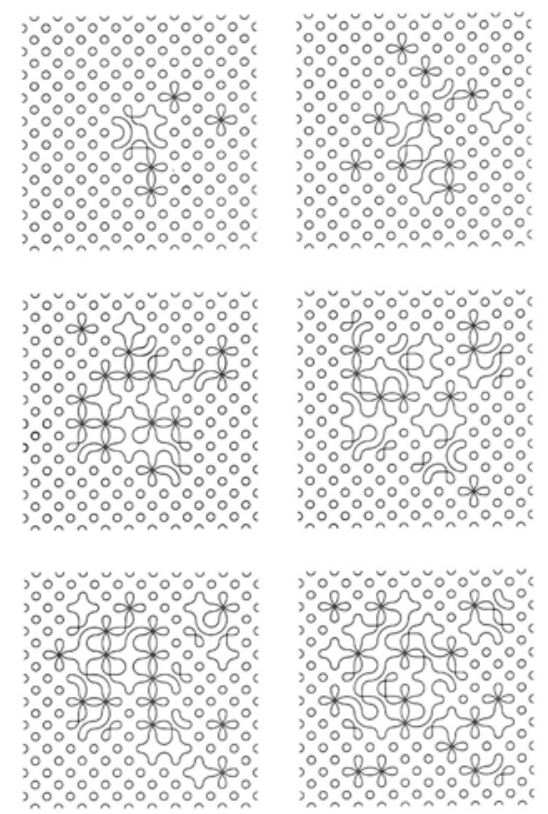

Fig. 5. Paul Brown, Lifemods Series1. 8 computer assisted drawings, ink on card, 1978-79.

Yet some artists were willing to throw themselves into the maelstrom and take on the strictures of the code. In 1978 the Computer Artists based at Malcolm Hughes Experimental and Electronic Art Department at the Slade School of Art published a catalogue of their recent graphics and sound work with the help of Jean Spencer. "Working Information" featured pieces including Chris Briscoe's generative audio, Darryl Viner's animations and plotted graphics by Peter Beyls [15]. The following year there was a student show "EXP at P.C.L." featuring Paul Brown's computer simulations, Steve Bell's interactive graphics and perceptual studies by Dominic Boreham [16]. The most striking feature was the sheer quantity of graphics and audio that was now being produced by computers, something approaching a continuous torrent of sensory data [Fig. 5].

The increasing continuity of the visual surface now possible in computer graphics made it very difficult for it to retain an explicable connection to the program that generated it. There was a kind of numerical image that flourished in SIGGRAPH Art Shows, IMAGINA conferences and glossy coffee table books like 'The Beauty of Fractals' [17]. This image was like the result of collections of different systematic components yet without an actual system itself - being guided instead by executive opportunism, scientific curiosity, engineering prowess and artistic confusion.

Unlike the Systems Artists, rising Conceptual 'systems' artists like Sol Le Witt and Adrian Piper were more openly critical and oppositional, self-reflexive and increasingly ironic. English Constructivists like Roy Ascott and Stephen Willats that were closer to this conceptual approach and less resolutely visual artists survived better, able to adapt their practice to a wider range of technological and discursive contexts. So too did the Computer Artists, who eventually found a practical outlet that could support their hunger for complexity and scale in the form of television production and other "creative 
industries" [18]. But for the Systems Constructivists there was nowhere left for them to go.

\section{THE SYSTEM OF SOFTWARE}

It was the internet that finally turned the computer into a mass medium and brought with it a new technology, a new audience and a new system - the network. Everyone now has to use software to work, to communicate, to spend their leisure time and so programming can become the subject of art as well as its technology. By the end of the nineties this shift was finally recognised in the emergence of "Software Art" - that the formation of subjectivity and social relations were now within the domain of software encoded exchanges [19]. For these reasons Software Art has seen itself within the tradition of Media Art or Conceptual Art rather than the progeny of Constructivism.

But this mass implementation of computing has also brought mass normalisation. By the end of the twentieth century the expectations of computer users had settled into universally accepted strictures of browser navigation, digital rights management, search engines and the standardisation of Object Orientated functionality [20]. To oppose these edifices much faith has been put in practices like Free and Open Source Software (FLOSS), yet without a creative agenda its main achievement to date has been free imitations of Microsoft applications. In the art world the dominant discourse of Conceptualism is also ill equipped to deal with the demands of software culture. The success of software and Software Art is dependent on the actualised contingencies of engaging with it directly, yet critics regularly evaluate software based art by reading publicity mailouts. Like conceptualism in art, government sponsored agencies and corporations use code to construct social reality in isolation from the full implications of that reality. And the means by which that code is itself constructed through the discipline of software engineering is also guided by standards designed to achieve industrial and commercial efficiency.

Systems were about process, computer programming was about control. Software is about fitting in, observing standards, listening to the message queue, relinquishing control over context. Under these conditions, where does the artist's 'system' end and software begin? The proliferation of materialities - codes, interfaces, platforms and output devices creates confusion about where the focus of our attention should lie and how to keep the construction 'open' under such conditions. Yet it is in the tracing of the passages and leaks between these levels that the art of the system now lies.

\section{CONCLUSIONS}

Systems Artists were the last programmers before the digital computer made that practice synonymous with itself. Through their intimate proximity to the many varieties of order they absorbed the programmatic into the very core of their thought processes until the logic of series, modularity and permutation became an indistinguishable part of their perceptions and sensibilities. But for an audience, the work could be as inscrutable as the most introspective of subjective art, as though each work a private programming language, emphatic yet utterly remote, produced by 'an intelligence on another planet'. Without the ability to share and disseminate their techniques more widely and without 
an external context for their work that was familiar to their audience, Systems artists diversification of the 'programmatic' turned in on itself. It became a hermetic practice a faint reminder of a kind of deliberate psychic objectification that has perhaps not been seen since the alchemists of the pre Enlightenment era aligned their own subjective inflections with the drama of chemical experiments.

Constructivists did retain a belief in the power of aesthetic and sensory perception to make a significant contribution to knowledge beyond the theoretical or cognitive. 'Precise feeling' can tackle problems that reason cannot formulate [21]. And Systems artists in particular integrated formal language into creative thought to the degree at which an artist can reclaim the rational as part of a more heterogeneous intuitive practice. There is now a fresh desire amongst artists to open up the wider expressive potential of formal logic and abstract machines beyond the atrophied state of software, to make code directly perceptible, embodied, 'affective'. Can a 'systematic means of expression' bring the operations of modern software within the human range that the Systems artists enjoyed yet retain a relevance to the complexities of the networked society? Can we use the wider range of expressive means that are now available in digital media to get such a practice out of an artists' head? It is at this current point in history that the problem of how discursive categories arise from computation, of how 'conceptual structures' and 'mathematical themes' might be realised in a form that has a relevance for the uninitiated might become more tractable.

The full version of this essay was written in 2006 and published in White Heat, Cold Logic: British Computer Arts 1960 - 1980, (ed.) Charlie Gere at al, Birkbeck College and MIT Press, 2009.

\section{ACKNOWLEDGEMENT}

This article was based on research supported by a grant from the Arts and Humanities Research Board. 


\section{References}

1. LISSITZKY, VAN DOESBURG AND RICHTER, "Statement by the International Faction of Constructivists" (1922). Reprinted in: Stephen Bann (ed.), The Tradition of Constructivism, Da Capo Press, 1990.

2. ibid.

3. NAUM GABO, "Sculpture Carving and Construction in Space”. In: Lesley Martin, Ben Nicholson and Naum Gabo (eds.), Circle: International Survey of Constructivist Art (1937), Paeger Publishers, New York 1971.

4. VICTOR PASMORE, "Developing Process". In: Anthony Hill (ed.), DATA: Direction in Art, Theory and Aesthetics, 1969. Faber and Faber, p 120.

5. MAX BILL, Structure. No. 2, 1961.

6. ANTHONY HILL, "The Structural Syndrome in Constructive Art". In: Gyorgy Kepes (ed), Module, Symmetry, Proportion, George Braziller, 1966.

7. KENNETH MARTIN, "Movement and Change" (1966). In: Anthony Hill (ed.), DATA: Direction in Art, Theory and Aesthetics, 1969. Faber and Faber. p 71.

8. MARY MARTIN, "Reflections" (1967). In: Anthony Hill (ed.), DATA: Direction in Art, Theory and Aesthetics, 1969. Faber and Faber. p 95.

9. KENNETH MARTIN, Structure, vol 6, no 1, 1964.

10. JEFFREY STEELE, statement in Stephen Bann (ed.) Systems, exhibition catalogue, Arts Council of England, 1972. pp 52-56.

11. ibid.

12. KENNETH MARTIN, "Construction and Change: Notes on a Group of Works Made Between 1965 and 1967”, Leonardo, vol 1 1968, pp 363-372.

13. JEAN SPENCER, statement in Stephen Bann (ed.) Systems, exhibition catalogue, Arts Council of England, 1972. pp 48-51.

14. RICHARD WRIGHT, "Programming with a Paintbrush: The Last Interactive Workstation" Filmwaves, no 12, Autumn 2000. pp 44-48. http://www.futurenatural.net/writings.html\#painting

15. "Working Information" catalogue, London 1978.

16. "EXP at P.C.L." exhibition catalogue. Concourse Gallery, Polytechnic of Central London, London, March 1979.

17. HEINZ-OTTO PEITGEN AND PETER RICHTER, The Beauty of Fractals, Springer Verlag, Berlin, 1986.

18. RICHARD WRIGHT, "More Power: The Pioneers of British Computer Animation and their Legacy" Published in Diverse Practices: A Critical Reader on British Video Art (ed.) by Julia Knight, Arts Council of England and University of Luton, 1996.

19. Jury Statement for “Artistic Software” award. Transmediale Festival, Berlin, 2001. http://www.transmediale.de/01/en/software.htm

20. RICHARD WRIGHT, "Software Art After Programming" MUTE no.28, spring 2004. pp 46-53.

21. GEOFFREY SMEDLEY, statement in Stephen Bann (ed.) Systems, exhibition catalogue, Arts Council of England, 1972. p 43.

Illustrations

1. Anthony Hill, Prime Rhythms (Constructional Relief). Perspex and vinyl sheet, 1958-60. (Coll. Adrian Heath, Clio Heath)

2. Mary Martin working on maquettes for "Tidal Movements", 1960. Courtesy Annely Juda Fine Art, London. Copyright the Estate of Mary Martin.

3. Kenneth Martin with Screw Mobile, 1967. Courtesy Annely Juda Fine Art, London. Copyright the Estate of Kenneth Martin.

4. Jeffrey Steele, Medusa. Oil on canvas, $914 \times 1219 \mathrm{~mm}, 1969$. Courtesy the artist.

5. Paul Brown, Lifemods Series 1. 8 computer assisted drawings, ink on card, 1978-79. 